\title{
Prevalence of Depression and Associated Relationship with Lifestyles in Chinese Adults with Multi-Level Generalized Estimation Equation Model
}

\section{Li Yuan ( $\triangle$ yuanli177451@163.com)}

Institute of Basic Medical Sciences,Chinese Academy of Medical Sciences\&School of Basic Medicine,Peking Union Medical College https://orcid.org/0000-0001-5298-8047

Tao Xu

Institute of Basic Medical Sciences,Chinese Academy of Medical Sciences\&School of Basic Medicine,Peking Union Medical College

Shaomei Han

Institute of Basic Medical Sciences,Chinese Academy of Medical Sciences \& School of Basic Medicine,Peking Union Medical College

\section{Research article}

Keywords: depression, prevalence, lifestyle, generalized estimation equation model

Posted Date: February 12th, 2021

DOI: https://doi.org/10.21203/rs.3.rs-223062/v1

License: (c) (i) This work is licensed under a Creative Commons Attribution 4.0 International License. Read Full License 


\section{Abstract}

\section{Background}

Most epidemiological surveys paid more attention to the occurrence of depression in the elderly and adolescents, while ignored the young and middle-aged people. Besides, depression resulted from a complex interaction of heredity, biochemistry, social, psychological and biological factors. The aim of our study was to examine the prevalence of depression and the relationship between depression and lifestyle factors in Chinese adults based on a large-scale cross-sectional survey.

Methods

The Composite International Diagnostic Interview Short Form for Major Depression was used to assess the depression status of all subjects. We used multi-level generalized estimating equation model to determine the relationship between depression and lifestyles.

Results

Of the 7985 respondents, 4252 were considered as being depressive with a prevalence of $53.25 \%$. After controlling for the cluster effect of living environment and confounding effect of demographic characteristics, the following factors increased the risk of depression: overweight(OR=1.269, 95\% Cl: 1.117-1.444), obesity(OR=1.415, 95\% Cl: 1.152-1.740), single status(OR=2.003, 95\% Cl: 1.635-2.457), alcohol drinking(OR=1.333, 95\% Cl: 1.137-1.563), sleeping less than $6 \mathrm{~h}$ a day $(\mathrm{OR}=1.485,95 \% \mathrm{Cl}: 1.267-$ 1.743), poor sleep quality ( $\mathrm{OR}=1.553,95 \% \mathrm{Cl}$ : 1.392-1.732), feeling stressed(OR=2.133, 95\% Cl: $1.744-$ 2.621), adverse life events( $\mathrm{OR}=1.513,95 \% \mathrm{Cl}$ : $1.333-1.718)$, unhealthy dietary patterns $(\mathrm{OR}=1.472,95 \% \mathrm{Cl}$ : 1.324-1.638), irregular meal times (OR=2.482, 95\% Cl: 2.138-2.887) and suboptimal health status(OR=7.919, 95\% Cl: 6.843-9.185). Those with medical insurance (OR=0.774, 95\% Cl: 0.649-0.921) was less likely to have depression.

Conclusions

Unhealthy lifestyles were found closely associated with depression. By altering lifestyle behaviors for the better, the depressive symptoms could be effectively improved.

\section{Introduction}

With the rapid development of society, work pressure and competition people are confronting with are also increasing. People tend to feel fatigued, or even suffer from psychological sickness under severe pressure. The incidence rate of depression in China has been increasing gradually in recent years. Depression is a kind of affective disorder with long-lasting depressed mood as the main clinical feature [1]. The core symptoms are "three low", that is, depressed mood, reduced energy, loss of interest and enjoyment, which also be accompanied by slow reaction, sleep disorder and poor concentration [2]. As a chronic mental disease, depression has the characteristics of high prevalence, high disability rate, high 
suicide rate, high comorbidity rate, high recurrence rate and high disease burden [3]. Depression can not only cause disorders of the nervous and endocrine system, leading to a variety of diseases, but also impair social function, resulting in problems such as inability to continue with social, work or domestic activities. At its worst, depression can lead to suicide, causing great harm to themselves and their families [4]. Globally, there are about 300 million to 400 million people suffering from depression, and the global prevalence is about 4.4\% [5]. In China, depression is the most common mental disorder with a lifetime prevalence of $6.9 \%$ and a 12-month prevalence of $3.6 \%$ [6]. Based on this prevalence, we estimate that there are more than 95 million depression patients in China. WHO lists MDD as the third cause of disease burden in the world and the first cause of disease burden in high- and middle-income countries [7]. Therefore, it is necessary to study depression, a major public health problem.

At present, most epidemiological surveys paid more attention to the occurrence of depression in special populations such as the elderly and pregnant women, while ignored the depression in young and middleaged people. China has entered an aging society since 1999 [8], chronic mental diseases such as depression in the elderly have seriously impaired the physical health, mental health and quality of life of the elderly[9]. However, it should be noted that the problem of disease care for the elderly and the sharp reduction in retirement income of the elderly have brought great pressure to the only-child family[10]. In addition, with the rapid development of economy and the intensification of social competition, the economic and spiritual burden of the young and middle-aged people has greatly increased, and various psychological stress factors of people have increased sharply. Therefore, the mental health of young and middle-aged people should also be paid enough attention.

Depression results from a complex interaction of heredity, biochemistry [11, 12], social, psychological and biological factors. Psychological and social environment factors are important factors affecting the occurrence and development of depression [13]. Adverse cultural and educational environment, tensional interpersonal relationship, unhappy marriage, unemployment and psychological trauma are all likely to lead to the occurrence of depression $[14,15]$. Depression is also highly correlated with lifestyle. Long-term unhealthy lifestyles not only lead to disorders of body functions, resulting in many chronic diseases, but is also closely related to the occurrence of depression. Lifestyle includes sleep time, sleep quality, stress, diet choices, smoking, exercise and so on.

In addition, people living in the same community may be affected by the same socioeconomic environment, while previous studies did not consider the clustering effect of similar living environment, which may have confounding effects on the accuracy of the research results on the relationship between adult depression and lifestyle. Therefore, the aim of the present study was to determine the prevalence of depression and associated factors in Chinese adults across a broad age range, above 18 years, using a large-scale, cross-sectional survey. A multi-level generalized estimation equation (GEE) was constructed to evaluate the relationship between depression and lifestyles, controlling for the cluster effect of location and the confounding effect of demographic characteristics.

\section{Materials And Methods}




\subsection{Sample and Participants}

The sample was taken from a large-scale population survey about Chinese people's physiological and psychological constants conducted in 2010. This survey was conducted in Yunnan Province, southwest of China and two-stage cluster sampling method was used. Firstly, two cities were sampled and then several communities and villages were randomly selected in the cities. In these selected communities, all the eligible individuals were surveyed: those aged 18 years old or above, who had not suffered from certain severe chronic diseases and had not experienced a high fever in the preceding 15 days. After providing written informed consent, the participants attended temporary physical examination centers voluntarily to take part in the survey. The study was approved by the ethics review board of the Institute of Basic Medical Sciences, Chinese Academy of Medical Sciences (No. 005-2008).

8,151 participants signed the informed consent form and were willing to take part in this survey, among which 7,985 participants completed all survey scales and the completion rate was $97.96 \%$.

\subsection{DefinitionA of Depression and Covariates}

The Composite International Diagnostic Interview Short Form for Major Depression was used to assess the depression status of all subjects $[16,17]$. Each subject was asked with seven questions about his or her feeling during the past year. If a subject has responded as 'yes' for one or more questions, he or she will be considered as being depressive.

Overweight and obesity was defined based on the Chinese Guidelines for the Prevention and Control of Adult Overweight and Obesity and the criteria of the Working Group on Obesity in China [18]. Overweight was defined by a body mass index $(B M I) \geq 24 \mathrm{~kg} / \mathrm{m} 2$, but $<28 \mathrm{~kg} / \mathrm{m} 2$, and obesity by a BMI $\geq 28 \mathrm{~kg} / \mathrm{m} 2$.

Stress and life event defined about whether the participant felt about some economic stress, life stress or work stress and negative events or positive events recently. Diet choice included a routine diet choice or an unhealthy diet choice and the unhealthy diet choice meant highly spicy, sweet, salty or greasy food. Irregular meal time indicated the participant could not have breakfast, lunch and dinner at fixed time period. Sub-health status was assessed with the Delphi sub-health scale $[19,20]$.

\subsection{Statistical Analysis}

The case report forms were double-checked and the raw data were inputted twice, by two data managers, to guarantee its accuracy and integration. All statistical analysis was performed by SAS9.4 software. P< 0.05 was defined as statistically significant. Continuous data were described with mean and standard deviation. Categorical data were described with numbers and percentages and compared using the chisquare test. A multi-level GEE model was used to determine the relationship between depression and lifestyles to control for the cluster effect of location and the confounding effect of demographic characteristics. Odds ratios (ORs) and their $95 \%$ confidence intervals (Cls) were used to assess the strength of each relationship. 


\section{Results}

The mean age of the 7,985 participants was $37.6 \pm 16.1$ years, that of the 3,073 men was $38.8 \pm 15.8$ years, and that of the 4,912 females was $36.9 \pm 16.3$ years. The participants were of dozens of ethnicities, including $\mathrm{Han}(5,034 ; 63.04 \%)$, Yi $(2,412 ; 30.21 \%)$, and others $(539 ; 6.75 \%) .37 .42 \%$ of all participants took mental work, such as teacher, doctor, professionals, students, governmental and institute employees et al. Percentages of current smokers and alcohol consumers were $21.16 \%$ and $17.58 \%$ respectively. Percent of overweight and obese participants were $21.96 \%$ and $71.2 \%$ respectively. 768 participants $(9.62 \%)$ reported feeling about strong stress in work, home or economy. 2040 participants $(25.55 \%)$ suffered from some positive or negative life events recently. $28.68 \%$ of all participants exercised regularly. $12.79 \%$ of all participants normally slept for $<6 \mathrm{~h}$ a day and only $36.66 \%$ of all participants reported good sleep quality. $59.97 \%$ of all participants habitually consumed a special diet and $16.18 \%$ of all participants could not have breakfast, lunch and dinner in fixed hours regularly. $89.04 \%$ of all participants had medical insurance.

Of all 7,985 participants, 4,252 reported one or many depression symptoms and the prevalence of depression was $53.25 \%$. The median number of depression symptoms was $1(0,2)$. The prevalence of depression in males $(49.11 \%)$ was lower than in females $(55.84 \%, \mathrm{P}<0.0001)$. The prevalence of depression was $60.07 \%$ in young participants, $44.66 \%$ in middle-aged participants, and $57.52 \%$ in older adult participants, and then the prevalence of depression was lowest in middle-aged participants $(\mathrm{P}<$ 0.0001). Among the ethnicities studied, Yi participants had a lower prevalence of depression $(39.26 \%)$ than Han (58.68\%) and others (65.12\%). Physical laborers had a lower prevalence (47.73\%) of depression than their counterparts (62.48\%). Married participants had a lower prevalence (47.07\%) than single ones $(64.52 \%)$ and widowed or divorced ones (65.12\%). The prevalence of depression was $43.50 \%$ in participants with primary school educational level, $56.98 \%$ in ones with middle school educational level, and $62.36 \%$ in ones with college educational level. The prevalence of depression increased gradually with educational level $(P<0.0001)$. Current smokers had a lower prevalence of depression $(49.47 \%)$ than their counterparts $(54.27 \%)$, but current alcohol consumers had a higher prevalence of depression $(55.91 \%)$ than their counterparts (52.68\%). Participants who normally slept for $<6 \mathrm{~h}$ a day had a higher prevalence of depression (64.84\%) than their counterparts (51.55\%). Participants who had a poor sleep quality had a higher prevalence of depression $(60.00 \%)$ than their counterparts $(41.58 \%)$. Respondents who felt about some stress $(78.78 \%$ VS $50.53 \%)$ or suffered from some life events $(67.45 \%$ VS $48.38 \%)$ had higher prevalence rates of depression than counterparts. Participants who habitually consumed a special diet $(59.62 \%)$ had higher prevalence of depression than their counterparts $(43.71 \%)$. Respondents who had breakfast, lunch and dinner at fixed hours regularly had lower prevalence rates of depression than counterparts (50.83\% VS 65.79\%). Respondents in sub-health status had higher prevalence rates of depression status than counterparts (60.41\% VS $25.37 \%)$. Compared with participants without medical insurance, those with medical insurance had lower prevalence rates of depression (51.97\% VS 63.66\%). The prevalence and factors related to depression, classified according to demographic characteristics, are listed in Table 1. 
Table 1

Prevalence (\%) of depression about demographic characteristics

\begin{tabular}{|c|c|c|c|c|c|}
\hline & Total & depression & & Chi-square $t$ & \\
\hline & & no & Yes & Chi-square & $P^{*}$ \\
\hline All subjects & 7985 & $3733(46.75 \%)$ & $4252(53.25 \%)$ & & \\
\hline Age (years) & & & & 175.7001 & $<0.0001$ \\
\hline $18-34$ & 3691 & 1474(39.93\%) & $2217(60.07 \%)$ & & \\
\hline $35-59$ & 3383 & 1872(55.34\%) & $1511(44.66 \%)$ & & \\
\hline$>=60$ & 911 & $387(42.48 \%)$ & $524(57.52 \%)$ & & \\
\hline Gender & & & & 34.4724 & $<0.0001$ \\
\hline Male & 3073 & $1564(50.89 \%)$ & $1509(49.11 \%)$ & & \\
\hline Female & 4912 & $2169(44.16 \%)$ & $2743(55.84 \%)$ & & \\
\hline Occupation & & & & 163.5198 & $<0.0001$ \\
\hline Physical laborer & 4997 & $2612(52.27 \%)$ & 2385(47.73\%) & & \\
\hline Mental laborer & 2988 & $1121(37.52 \%)$ & $1867(62.48 \%)$ & & \\
\hline Marrital status & & & & 218.0576 & $<0.0001$ \\
\hline Married & 5097 & $2698(52.93 \%)$ & 2399(47.07\%) & & \\
\hline Single & 2652 & $941(35.48 \%)$ & $1711(64.52 \%)$ & & \\
\hline Widowed or divorced & 236 & $94(39.83 \%)$ & $142(60.17 \%)$ & & \\
\hline Education level & & & & 204.4340 & $<0.0001$ \\
\hline Primary school & 3069 & $1734(56.50 \%)$ & $1335(43.50 \%)$ & & \\
\hline Middle school & 2759 & 1187(43.02\%) & 1572(56.98\%) & & \\
\hline College & 2157 & $812(37.64 \%)$ & $1345(62.36 \%)$ & & \\
\hline Smoker & & & & 12.3196 & 0.0004 \\
\hline No & 6295 & $2879(45.73 \%)$ & $3416(54.27 \%)$ & & \\
\hline Yes & 1690 & $854(50.53 \%)$ & $836(49.47 \%)$ & & \\
\hline Alcohol drinker & & & & 4.8485 & 0.0277 \\
\hline No & 6581 & $3114(47.32 \%)$ & $3467(52.68 \%)$ & & \\
\hline Yes & 1404 & $619(44.09 \%)$ & $785(55.91 \%)$ & & \\
\hline
\end{tabular}




\begin{tabular}{|c|c|c|c|c|c|}
\hline & Total & depression & & Chi-square $t$ & \\
\hline & & no & Yes & Chi-square & $P^{*}$ \\
\hline Ethnicity & & & & 279.7303 & $<0.0001$ \\
\hline Han & 5034 & $2080(41.32 \%)$ & $2954(58.68 \%)$ & & \\
\hline$Y i$ & 2412 & $1465(60.74 \%)$ & $947(39.26 \%)$ & & \\
\hline Others & 539 & $188(34.88 \%)$ & $351(65.12 \%)$ & & \\
\hline BMI & & & & 1.9884 & 0.3700 \\
\hline Normal & 5685 & $2681(47.16 \%)$ & $3004(52.84 \%)$ & & \\
\hline Overweight & 1755 & $811(46.21 \%)$ & $944(53.79 \%)$ & & \\
\hline Obesity & 545 & $241(44.22 \%)$ & $304(55.78 \%)$ & & \\
\hline Sleep duration & & & & 63.1537 & $<0.0001$ \\
\hline$>=$ Six hours & 6964 & $3374(48.45 \%)$ & $3590(51.55 \%)$ & & \\
\hline$<$ six hours & 1021 & $359(35.16 \%)$ & $662(64.84 \%)$ & & \\
\hline Sleep quality & & & & 252.8518 & $<0.0001$ \\
\hline Good & 2927 & $1710(58.42 \%)$ & $1217(41.58 \%)$ & & \\
\hline Poor & 5058 & $2023(40.00 \%)$ & $3035(60.00 \%)$ & & \\
\hline Stress & & & & 222.4079 & $<0.0001$ \\
\hline No & 7217 & $3570(49.47 \%)$ & $3647(50.53 \%)$ & & \\
\hline Yes & 768 & $163(21.22 \%)$ & $605(78.78 \%)$ & & \\
\hline Life event & & & & 221.9719 & $<0.0001$ \\
\hline No & 5945 & $3069(51.62 \%)$ & $2876(48.38 \%)$ & & \\
\hline Yes & 2040 & $664(32.55 \%)$ & $1376(67.45 \%)$ & & \\
\hline Regular exercise & & & & 0.5227 & 0.4697 \\
\hline No & 5695 & $2677(47.01 \%)$ & $3018(52.99 \%)$ & & \\
\hline Yes & 2290 & $1056(46.11 \%)$ & 1234(53.89\%) & & \\
\hline Diet choice & & & & 194.7767 & $<0.0001$ \\
\hline Routine & 3196 & 1799(56.29\%) & 1397(43.71\%) & & \\
\hline Unhealthy & 4733 & $1934(40.38 \%)$ & $2855(59.62 \%)$ & & \\
\hline Meal time & & & & 97.3609 & $<0.0001$ \\
\hline
\end{tabular}




\begin{tabular}{|llllll|}
\hline & Total & depression & \multicolumn{2}{c|}{ Chi-square test } \\
\cline { 3 - 6 } & & no & Yes & Chi-square & $P^{*}$ \\
\hline Regular & 6693 & $3291(49.17 \%)$ & $3402(50.83 \%)$ & \\
\hline Irregular & 1292 & $442(34.21 \%)$ & $850(65.79 \%)$ & & \\
\hline Sub-health status & & & & 640.5732 & $<0.0001$ \\
\hline No & 1632 & $1218(74.63 \%)$ & $414(25.37 \%)$ & & \\
\hline Yes & 6353 & $2515(39.59 \%)$ & $3838(60.41 \%)$ & & \\
\hline Medical insurance & & & & 42.7551 & $<0.0001$ \\
\hline No & 875 & $318(36.34 \%)$ & $557(63.66 \%)$ & & \\
\hline Yes & 7110 & $3415(48.03 \%)$ & $3695(51.97 \%)$ & & \\
\hline
\end{tabular}

Table 2 shows the results of the univariate and multivariate multi-level GEE models constructed using the factors associated with depression. After controlling for the cluster effect of location and the confounding effect of other covariates, no significant associations were found between smoking status or exercise and depression. Compared with young participants, middle-aged $(\mathrm{OR}=0.812,95 \% \mathrm{Cl}$ : $0.687-$ 0.960) had lower prevalence of depression. Compared with participants with primary school educational level, participants with middle school educational level $(\mathrm{OR}=1.462,95 \% \mathrm{Cl}: 1.171-1.826)$ and participants with college educational level $(\mathrm{OR}=1.354,95 \% \mathrm{Cl}: 1.172-1.565)$ had higher prevalence of depression. Compared with normal-weight participants, overweight $(\mathrm{OR}=1.269,95 \% \mathrm{Cl}: 1.117-1.444)$ and obese participants ( $\mathrm{OR}=1.415,95 \% \mathrm{Cl}$ : 1.152-1.740) had higher prevalence of depression. Thus, having a higher BMI or educational level increases the risk of depression. Compared with Hans, Yis (OR = $0.498,95 \% \mathrm{Cl}$ : $0.438-0.566)$ were less likely to have depression. 
Table 2

Risk factors associated with depression with multi-level GEE model

\begin{tabular}{|c|c|c|c|c|}
\hline \multirow[t]{2}{*}{ Characteristics } & \multicolumn{2}{|c|}{ Univariate } & \multicolumn{2}{|c|}{ Multivariate } \\
\hline & OR & $95 \% \mathrm{Cl}$ & OR & $95 \% \mathrm{Cl}$ \\
\hline \multicolumn{5}{|l|}{ Age (years) } \\
\hline $18-34$ & 1.000 & - & 1.000 & - \\
\hline $35-59$ & 0.537 & $0.488-0.590$ & 0.812 & $0.687-0.960$ \\
\hline$>=60$ & 0.900 & $0.777-1.043$ & 1.189 & $0.947-1.492$ \\
\hline \multicolumn{5}{|l|}{ Gender } \\
\hline Male & 1.000 & - & 1.000 & - \\
\hline Female & 1.311 & $1.197-1.435$ & 1.384 & $1.211-1.582$ \\
\hline \multicolumn{5}{|l|}{ Occupation } \\
\hline Physical laborer & 1.000 & - & 1.000 & - \\
\hline Mental laborer & 1.824 & $1.663-2.001$ & 1.293 & $1.075-1.556$ \\
\hline \multicolumn{5}{|l|}{ Marrital status } \\
\hline Married & 1.000 & - & 1.000 & - \\
\hline Single & 2.045 & $1.857-2.253$ & 2.003 & $1.635-2.457$ \\
\hline Widowed or divorced & 1.699 & $1.304-2.223$ & 1.155 & $0.856-1.563$ \\
\hline \multicolumn{5}{|l|}{ Education level } \\
\hline Primary school & 1.000 & - & 1.000 & - \\
\hline Middle school & 1.720 & $1.551-1.909$ & 1.462 & $1.171-1.826$ \\
\hline College & 2.151 & $1.923-2.408$ & 1.354 & $1.172-1.565$ \\
\hline \multicolumn{5}{|l|}{ Smoker } \\
\hline No & 1.000 & - & 1.000 & - \\
\hline Yes & 0.825 & $0.741-0.919$ & 0.972 & $0.829-1.138$ \\
\hline \multicolumn{5}{|l|}{ Alcohol drinker } \\
\hline No & 1.000 & - & 1.000 & - \\
\hline Yes & 1.139 & $1.015-1.279$ & 1.333 & $1.137-1.563$ \\
\hline \multicolumn{5}{|l|}{ Ethnicity } \\
\hline
\end{tabular}




\begin{tabular}{|c|c|c|c|c|}
\hline \multirow[t]{2}{*}{ Characteristics } & \multicolumn{2}{|c|}{ Univariate } & \multicolumn{2}{|c|}{ Multivariate } \\
\hline & OR & $95 \% \mathrm{Cl}$ & OR & $95 \% \mathrm{Cl}$ \\
\hline Han & 1.000 & - & 1.000 & - \\
\hline Yi & 0.455 & $0.412-0.502$ & 0.498 & $0.438-0.566$ \\
\hline Others & 1.315 & $1.093-1.585$ & 1.018 & $0.820-1.267$ \\
\hline \multicolumn{5}{|l|}{ BMI } \\
\hline Normal & 1.000 & - & 1.000 & - \\
\hline Overweight & 1.039 & $0.933-1.157$ & 1.269 & $1.117-1.444$ \\
\hline Obesity & 1.125 & $0.944-1.344$ & 1.415 & $1.152-1.740$ \\
\hline \multicolumn{5}{|l|}{ Sleep duration } \\
\hline$>=$ Six hours & 1.000 & - & 1.000 & - \\
\hline$<$ six hours & 1.733 & $1.513-1.989$ & 1.485 & $1.267-1.743$ \\
\hline \multicolumn{5}{|l|}{ Sleep quality } \\
\hline Good & 1.000 & - & 1.000 & - \\
\hline Poor & 2.108 & $1.922-2.313$ & 1.553 & $1.392-1.732$ \\
\hline \multicolumn{5}{|l|}{ Stress } \\
\hline No & 1.000 & - & 1.000 & - \\
\hline Yes & 3.633 & $3.046-4.358$ & 2.133 & $1.744-2.621$ \\
\hline \multicolumn{5}{|l|}{ Life event } \\
\hline No & 1.000 & - & 1.000 & - \\
\hline Yes & 2.211 & $1.990-2.459$ & 1.513 & $1.333-1.718$ \\
\hline \multicolumn{5}{|l|}{ Regular exercise } \\
\hline No & 1.000 & - & 1.000 & - \\
\hline Yes & 1.037 & $0.941-1.142$ & 0.925 & $0.821-1.042$ \\
\hline \multicolumn{5}{|l|}{ Diet choice } \\
\hline Routine & 1.000 & - & 1.000 & - \\
\hline Unhealthy & 1.901 & $1.736-2.082$ & 1.472 & $1.324-1.638$ \\
\hline Meal time & & & & \\
\hline
\end{tabular}




\begin{tabular}{|lllll|}
\hline Characteristics & \multicolumn{2}{l}{ Univariate } & \multicolumn{2}{l|}{ Multivariate } \\
\cline { 2 - 5 } & OR & $95 \% \mathrm{Cl}$ & OR & $95 \% \mathrm{Cl}$ \\
\hline Regular & 1.000 & - & 1.000 & - \\
\hline Irregular & 1.860 & $1.643-2.108$ & 2.482 & $2.138-2.887$ \\
\hline Sub-health status & & & \\
\hline No & 1.000 & - & 1.000 & - \\
\hline Yes & 4.490 & $3.976-5.078$ & 7.919 & $6.843-9.185$ \\
\hline Medical insurance & & & & \\
\hline No & 1.000 & - & 1.000 & - \\
\hline Yes & 0.618 & $0.534-0.714$ & 0.774 & $0.649-0.921$ \\
\hline * OR: Odds ratio; Cl: confidence interval; GEE: generalized estimation equation \\
\hline
\end{tabular}

Females $(\mathrm{OR}=1.384,95 \% \mathrm{Cl}: 1.211-1.582)$, laborers with mental workers $(\mathrm{OR}=1.293,95 \% \mathrm{Cl}: 1.075-$ 1.556), single participants $(\mathrm{OR}=2.003,95 \% \mathrm{Cl}: 1.635-2.457)$, current drinkers $(\mathrm{OR}=1.333,95 \% \mathrm{Cl}$ : $1.137-1.563)$, those who typically slept for $<6 \mathrm{~h}$ a day $(\mathrm{OR}=1.485,95 \% \mathrm{Cl}: 1.267-1.743)$, those with poor sleep quality $(\mathrm{OR}=1.553,95 \% \mathrm{Cl}: 1.392-1.732)$, those feeling some stress $(\mathrm{OR}=2.133,95 \% \mathrm{Cl}$ : $1.744-2.621)$ or with life event $(\mathrm{OR}=1.513,95 \% \mathrm{Cl}: 1.333-1.718)$, those consuming a special diet $(\mathrm{OR}=$ $1.472,95 \% \mathrm{Cl}: 1.324-1.638)$, those without regular meal time (OR $=2.482,95 \% \mathrm{Cl}: 2.138-2.887)$, and those in sub-health status (OR $=7.919,95 \% \mathrm{Cl}: 6.843-9.185)$ had higher risk of depression. Compared with participants without medical insurance, those with medical insurance $(\mathrm{OR}=0.774,95 \% \mathrm{Cl}: 0.649-$ 0.921 ) was less likely to have depression.

In summary, after controlling for the cluster effect of location, age, gender, occupation, marital status, educational level, current alcohol consumption, ethnicity, BMI, sleep duration, sleep quality, stress, life event, diet choice, meal time, sub-health status, and medical insurance were associated with depression.

\section{Discussion}

In our research, we verified that some factors including overweight, obesity, stress, adverse life events, excessive drinking, unhealthy dietary patterns, irregular meal times, short sleep duration, poor sleep quality, lack of medical insurance and being in a sub-health status will increase the risk of depression.

This study observed that smokers have lower risk of depression than non-smokers. After using the multivariate GEE model, it was found that there was no significant correlation between smoking and depression. It was speculated that the observed association between smoking and mental health might be the result of common genetic and environmental factors. Nicotine reported in a review that relevant studies have shown that smoking can increase the risk of depression[21]. There are also studies have 
shown that smoking can relieve depression after suffering from depression, so depression is a susceptible factor of smoking [22]. However, the overall conclusions are still inconsistent at present, and few studies support the two-way relationship between smoking and depression [23], which requires strong causal inference [21].

In the longitudinal study of Gemes'K, mild and moderate drinkers have lower risk of depression than nondrinkers, but excessive drinking can increase the risk of depression [24]. On one hand, alcoholics often find it difficult to control their emotions and behaviors, which can easily lead to family conflicts. Longterm alcohol abuse is one of the main reasons for divorce, and it will also cause resistance to work. On the other hand, alcoholism will lead to changes in body metabolism. Overall, adverse life events and damage of physical health will make people more prone to suffer from depression [25].

There is insufficient evidence in previous studies to support that less physical activity is a risk factor of depression, which can only show that it affects the development or continuation of depression to some extent, that is, people with depression who have less physical activity are more likely to have continued depression over time[26]. Teychenne's research confirms that sedentary lifestyle is related to the increased risk of depression [27], and this research shows that the risk of physical workers is lower than that of mental workers. Although there is no significant association between regular exercise and depression in our study, previous studies show that exercise has a positive effect on the prevention and treatment of depression[28, 29].

In this study, we observed that unhealthy dietary patterns increased the risk of depression, and previous studies have shown that healthy dietary patterns are associated with low-level depression prevalence[30]. For example, Mediterranean diet includes vegetables, fruits, nuts, grains, beans, fish, and full-fat yogurt, and the intake of these dietary components can ameliorate the symptoms of depression, while unhealthy dietary patterns such as fast food and high-fat diet are directly related to depression[27, 31].

Some researches show that people with depression have higher levels of obesity [32], and there is sufficient evidence that obesity is a risk factor of depression. The underlying mechanism may be twofold. Psychologically, people's ridicule to obesity brings stigma to obese people, and social pressure may even lead to their suicidal thoughts. Physiologically, obese people suffer more severe impairment of body functions [33]. Although the pathogenesis of diseases is different, the common biological mechanisms of depression and obesity are the over-activation of the hypothalamic-pituitary-adrenal axis (HPA axis) and the dysregulation of stress response system [34].

Short sleep duration and poor sleep quality are both closely associated with higher risk of depression [35, 36]. Insomnia is one of the most common prodromal features of depression, and $40 \%$ of cases have insomnia symptoms before the onset of depression. A meta-analysis has confirmed that the risk of depression in non-depressed people with insomnia is expected to increase by twice compared with those without sleep disorder [27, 37]. Many studies have confirmed that insufficient sleep and sleep disorders are related to many chronic diseases, such as hypertension, cancer, obesity and diabetes, as well as higher mortality [38-41]. 
The high-level prevalence of mental disorders has become a serious public health problem, and the development of mental health requires government support at all levels. Otherwise, the Ministry of Mental Health will be difficult to independently complete the management of psychotic patients [42]. Many studies have shown that access to health insurance can improve health. For example, when receiving emergency services, the psychological burden is small, and the decision-making time required is shortened, thus grasping the best time to treat diseases and improving the cure rate. However, the participants without medical insurance have higher risk of depression than those with medical insurance [43], which may be due to the fact that the participants with medical insurance do not have to worry about the cost of treatment, and they are more willing to ask professional doctors for help, thus improving the utilization rate of health care [44], which is consistent with the result of our study.

Sub-health is the intermediate state between health and disease [45], which is characterized by disorders of mental behavior or physiological characteristics or certain physical examination indexes and has no typical pathological characteristics [46]. Our study found that sub-health status increased the epidemic risk of depression by about 8 times.

Compared with the national prevalence of depression of 3.6\% [6],the prevalence of depression obtained in our study is higher, and the difference in the prevalence of depression between different studies can be attributed to the different tools for evaluating depression to some extent [47]. The limitation of this study is to use the CIDI-SFMD questionnaire as the diagnostic tool, and CIDI-SFMD is a brief description of the full version of CIDI [48]. Its problem is relatively rough [49], and it does not contain as many details as the full version of CIDI [50], which may lead to lack of specificity, overestimating the prevalence of depression [23]. It is also inevitable that mental illness is assessed by self-reported symptoms, which represent a possible clinical diagnosis rather than a definitive clinical diagnosis. Therefore, we cannot exclude that self-reported symptoms may be affected by recall bias [51, 52]. Another limitation has to be mentioned. Due to the cross-sectional design, it is impossible to verify the causal relationship between depression and lifestyles, which need to be researched further in a prospective study.

\section{Conclusions}

As a serious public health challenge, depression need be attached more attention in Chinese adults. Unhealthy lifestyles were found closely associated with depression, including current alcohol consumption, overweight, obesity, less sleep duration, poor sleep quality, unhealthy diet choice, irregular meal time, stress, life event, without medical insurance and sub-health status. By changing these lifestyle behaviors for the better, depression could be effectively improved.

\section{Declarations}

\section{Ethics approval and consent to participate}


The study was approved by the ethics review board of the Institute of Basic Medical Sciences, Chinese Academy of Medical Sciences (No. 005-2008). All included subjects gave their written informed consent forms to participate in the study.

\section{Consent for publications}

All participants gave verbal or written consent for their accounts to be anonymously published.

\section{Availability of data and material}

Data are held at the Institute of Basic Medical Sciences, Chinese Academy of Medical Sciences. All relevant data are within the paper.

\section{Competing interests}

The authors declare that they have no competing interests.

\section{Funding}

This work is supported by CAMS Innovation Fund for Medical Sciences $₫ 2018-12 M-A I-009)$ and the basic performance key project by the Ministry of Science and Technology of the People's Republic of China (No. 2006FY110300).

\section{Authors' Contributions}

LY drafted the manuscript. TX participated in the design of the study, preformed the statistical analysis and reviewed the manuscript. SH conceived of the study and participated in its design. All authors read and approved the final manuscript.

\section{Acknowledgements}

We wish to thank all of the subjects who gave their time so generously to participate in the research.

\section{References}

1. Willner, P., Scheel-Kruger, J., \& Belzung, C. (2013). The neurobiology of depression and antidepressant action. Neurosci Biobehav Rev, 37(10 Pt 1), 2331-2371, doi:10.1016/j.neubiorev.2012.12.007. 
2. Malhi, G. S., Bassett, D., Boyce, P., Bryant, R., Fitzgerald, P. B., Fritz, K., et al. (2015). Royal Australian and New Zealand College of Psychiatrists clinical practice guidelines for mood disorders. Aust N Z J Psychiatry, 49(12), 1087-1206, doi:10.1177/0004867415617657.

3. Wei, Q., \& Shanshan, G. (2014). New progress in treatment of depression. Journal of Third Military Medical University.

4. Hawton, K., Casanas, I. C. C., Haw, C., \& Saunders, K. (2013). Risk factors for suicide in individuals with depression: a systematic review. J Affect Disord, 147(1-3), 17-28, doi:10.1016/j.jad.2013.01.004.

5. Depression and Other Common Mental Disorders: Global Health Estimates. Geneva: World Health Organization; 2017. Licence: CC BY-NC-SA 3.0 IGO.

6. Huang, Y., Wang, Y., Wang, H., Liu, Z., Yu, X., Yan, J., et al. (2019). Prevalence of mental disorders in China: a cross-sectional epidemiological study. The lancet. Psychiatry, 6(3), 211-224, doi:10.1016/S2215-0366(18)30511-X.

7. Hirschfeld, R. M. (2012). The epidemiology of depression and the evolution of treatment. J Clin Psychiatry, 73 Supp/ 1, 5-9, doi:10.4088/JCP.11096su1c.01.

8. Lin, X., Xiong, D., Peng, Y. Q., Sheng, Z. F., Wu, X. Y., Wu, X. P., et al. (2015). Epidemiology and management of osteoporosis in the People's Republic of China: current perspectives. Clin Interv Aging, 10, 1017-1033, doi:10.2147/CIA.S54613.

9. Alexopoulos, G. S. (2005). Depression in the elderly. The Lancet, 365(9475), 1961-1970, doi:10.1016/s0140-6736(05)66665-2.

10. Wang, H. M. (2019). [Attaching importance to health of elderly population and promoting national healthy ageing actively in China]. Zhonghua liu xing bing xue za zhi = Zhonghua liuxingbingxue zazhi, 40(3), 259-265, doi:10.3760/cma.j.issn.0254-6450.2019.03.002.

11. Capuron, L., \& Miller, A. H. (2011). Immune system to brain signaling: neuropsychopharmacological implications. Pharmacol Ther, 130(2), 226-238, doi:10.1016/j.pharmthera.2011.01.014.

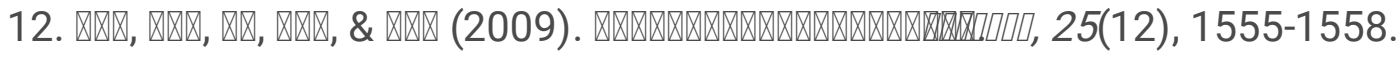

13. Meng, X., Brunet, A., Turecki, G., Liu, A., D'Arcy, C., \& Caron, J. (2017). Risk factor modifications and depression incidence: a 4-year longitudinal Canadian cohort of the Montreal Catchment Area Study. BMJ Open, 7(6), e015156, doi:10.1136/bmjopen-2016-015156.

14. Hammen, C. (2018). Risk Factors for Depression: An Autobiographical Review. Annu Rev Clin Psychol, 14, 1-28, doi:10.1146/annurev-clinpsy-050817-084811.

15. Madsen, I. E. H., Nyberg, S. T., Magnusson Hanson, L. L., Ferrie, J. E., Ahola, K., Alfredsson, L., et al. (2017). Job strain as a risk factor for clinical depression: systematic review and meta-analysis with additional individual participant data. Psychol Med, 47(8), 1342-1356, doi:10.1017/S003329171600355X.

16. Patten, S. B. (1997). Performance of the Composite International Diagnostic Interview Short Form for major depression in community and clinical samples. Chronic diseases in Canada, 18(3), 109-112. 
17. Patten, S. B., Brandon-Christie, J., Devji, J., \& Sedmak, B. (2000). Performance of the composite international diagnostic interview short form for major depression in a community sample. Chronic diseases in Canada, 21(2), 68-72.

18. Zhou, B.-F. (2002). Effect of body mass index on all-cause mortality and incidence of cardiovascular diseases-report for meta-analysis of prospective studies open optimal cut-off points of body mass index in Chinese adults. Biomedical and environmental sciences : BES, 15(3), 245-252.

19. Xu, T., Zhu, G., \& Han, S. (2020). Prevalence of Suboptimal Health Status and the Relationships between Suboptimal Health Status and Lifestyle Factors among Chinese Adults Using a Multi-Level Generalized Estimating Equation Model. International journal of environmental research and public health, 17(3), doi:10.3390/ijerph17030763.

20. Qing-Shan, C., Sheng-Yong, W., \& Chun-Xia, J. (2003). Evaluation on diagnositic criterion of subhealth with Delphi method. China Public Health.

21. Fluharty, M., Taylor, A. E., Grabski, M., \& Munafo, M. R. (2017). The Association of Cigarette Smoking With Depression and Anxiety: A Systematic Review. Nicotine Tob Res, 19(1), 3-13, doi:10.1093/ntr/ntw140.

22. Paperwalla, K. N., Levin, T. T., Weiner, J., \& Saravay, S. M. (2004). Smoking and depression. Med Clin North Am, 88(6), 1483-1494, x-xi, doi:10.1016/j.mcna.2004.06.007.

23. Khaled, S. M., Bulloch, A., Exner, D. V., \& Patten, S. B. (2009). Cigarette smoking, stages of change, and major depression in the Canadian population. Canadian journal of psychiatry. Revue canadienne de psychiatrie, 54(3), 204-208.

24. Gemes, K., Forsell, Y., Janszky, I., Laszlo, K. D., Lundin, A., Ponce De Leon, A., et al. (2019). Moderate alcohol consumption and depression - a longitudinal population-based study in Sweden. Acta Psychiatr Scand, 139(6), 526-535, doi:10.1111/acps.13034.

25. Boden, J. M., \& Fergusson, D. M. (2011). Alcohol and depression. Addiction, 106(5), 906-914, doi:10.1111/j.1360-0443.2010.03351.x.

26. Cabello, M., Miret, M., Caballero, F. F., Chatterji, S., Naidoo, N., Kowal, P., et al. (2017). The role of unhealthy lifestyles in the incidence and persistence of depression: a longitudinal general population study in four emerging countries. Global Health, 13(1), 18, doi:10.1186/s12992-017-0237-5.

27. Lopresti, A. L., Hood, S. D., \& Drummond, P. D. (2013). A review of lifestyle factors that contribute to important pathways associated with major depression: diet, sleep and exercise. J Affect Disord, 148(1), 12-27, doi:10.1016/j.jad.2013.01.014.

28. Wegner, M., Helmich, I., Machado, S., Nardi, A. E., Arias-Carrion, O., \& Budde, H. (2014). Effects of exercise on anxiety and depression disorders: review of meta- analyses and neurobiological mechanisms. CNS \& neurological disorders drug targets, 13(6), 1002-1014.

29. Strohle, A. (2009). Physical activity, exercise, depression and anxiety disorders. J Neural Transm (Vienna), 116(6), 777-784, doi:10.1007/s00702-008-0092-x.

30. Owen, L., \& Corfe, B. (2017). The role of diet and nutrition on mental health and wellbeing. Proc Nutr Soc, 76(4), 425-426, doi:10.1017/S0029665117001057. 
31. Masana, M. F., Haro, J. M., Mariolis, A., Piscopo, S., Valacchi, G., Bountziouka, V., et al. (2018). Mediterranean diet and depression among older individuals: The multinational MEDIS study. Exp Gerontol, 110, 67-72, doi:10.1016/j.exger.2018.05.012.

32. Allison, D. B., Newcomer, J. W., Dunn, A. L., Blumenthal, J. A., Fabricatore, A. N., Daumit, G. L., et al. (2009). Obesity among those with mental disorders: a National Institute of Mental Health meeting report. Am J Prev Med, 36(4), 341-350, doi:10.1016/j.amepre.2008.11.020.

33. Faith, M. S., Butryn, M., Wadden, T. A., Fabricatore, A., Nguyen, A. M., \& Heymsfield, S. B. (2011). Evidence for prospective associations among depression and obesity in population-based studies. Obes Rev, 12(5), e438-453, doi:10.1111/j.1467-789X.2010.00843.x.

34. Bornstein, S. R., Schuppenies, A., Wong, M. L., \& Licinio, J. (2006). Approaching the shared biology of obesity and depression: the stress axis as the locus of gene-environment interactions. Mol Psychiatry, 11(10), 892-902, doi:10.1038/sj.mp.4001873.

35. Chang, P. P., Ford, D. E., Mead, L. A., Cooper-Patrick, L., \& Klag, M. J. (1997). Insomnia in young men and subsequent depression. The Johns Hopkins Precursors Study. American journal of epidemiology, 146(2), 105-114.

36. Szklo-Coxe, M., Young, T., Peppard, P. E., Finn, L. A., \& Benca, R. M. (2010). Prospective associations of insomnia markers and symptoms with depression. Am J Epidemiol, 171(6), 709-720, doi:10.1093/aje/kwp454.

37. Paudel, M., Taylor, B. C., Ancoli-Israel, S., Blackwell, T., Maglione, J. E., Stone, K., et al. (2013). Sleep Disturbances and Risk of Depression in Older Men. Sleep, 36(7), 1033-1040, doi:10.5665/sleep.2804.

38. Holliday, E. G., Magee, C. A., Kritharides, L., Banks, E., \& Attia, J. (2013). Short sleep duration is associated with risk of future diabetes but not cardiovascular disease: a prospective study and metaanalysis. PLoS One, 8(11), e82305, doi:10.1371/journal.pone.0082305.

39. Cappuccio, F. P., Taggart, F. M., Kandala, N.-B., Currie, A., Peile, E., Stranges, S., et al. (2008). Metaanalysis of short sleep duration and obesity in children and adults. Sleep, 31(5), 619-626.

40. Cappuccio, F. P., D'Elia, L., Strazzullo, P., \& Miller, M. A. (2010). Sleep duration and all-cause mortality: a systematic review and meta-analysis of prospective studies. Sleep, 33(5), 585-592.

41. Wang, Q., Xi, B., Liu, M., Zhang, Y., \& Fu, M. (2012). Short sleep duration is associated with hypertension risk among adults: a systematic review and meta-analysis. Hypertens Res, 35(10), 1012-1018, doi:10.1038/hr.2012.91.

42. Liu, J., Ma, H., He, Y.-L., Xie, B., Xu, Y.-F., Tang, H.-Y., et al. (2011). Mental health system in China: history, recent service reform and future challenges. World psychiatry : official journal of the World Psychiatric Association (WPA), 10(3), 210-216.

43. Tian, D., Qu, Z., Wang, X., Guo, J., Xu, F., Zhang, X., et al. (2012). The role of basic health insurance on depression: an epidemiological cohort study of a randomized community sample in northwest China. BMC Psychiatry, 12, 151, doi:10.1186/1471-244X-12-151.

44. Green, C. A. (2004). Increasing age, minority ethnic origin, and lack of sufficient medical insurance decrease likelihood of treatment for depression in the elderly. Evidence-based mental health, 7(2), 58. 
45. Wang, W., \& Yan, Y. (2012). Suboptimal health: a new health dimension for translational medicine. Clinical and translational medicine, 1(1), 28, doi:10.1186/2001-1326-1-28.

46. Li, G., Xie, F., Yan, S., Hu, X., Jin, B., Wang, J., et al. (2013). Subhealth: definition, criteria for diagnosis and potential prevalence in the central region of China. BMC public health, 13, 446, doi:10.1186/1471-2458-13-446.

47. Yang, L. H., \& Link, B. G. (2009). Comparing diagnostic methods for mental disorders in China. Lancet (London, England), 373(9680), 2002-2004, doi:10.1016/S0140-6736(09)61091-6.

48. Wang, J., Williams, J., Lavorato, D., Schmitz, N., Dewa, C., \& Patten, S. B. (2010). The incidence of major depression in Canada: the National Population Health Survey. J Affect Disord, 123(1-3), 158163, doi:10.1016/j.jad.2009.07.016.

49. Wang, J., \& Patten, S. B. (2002). The moderating effects of coping strategies on major depression in the general population. Canadian journal of psychiatry. Revue canadienne de psychiatrie, 47(2), 167173.

50. Liu, N., Pan, X. F., Yu, C., Lv, J., Guo, Y., Bian, Z., et al. (2016). Association of Major Depression With Risk of Ischemic Heart Disease in a Mega-Cohort of Chinese Adults: The China Kadoorie Biobank Study. J Am Heart Assoc, 5(12), doi:10.1161/JAHA.116.004687.

51. Brailean, A., Curtis, J., Davis, K., Dregan, A., \& Hotopf, M. (2020). Characteristics, comorbidities, and correlates of atypical depression: evidence from the UK Biobank Mental Health Survey. Psychol Med, 50(7), 1129-1138, doi:10.1017/S0033291719001004.

52. Patten, S. B. (2003). Recall bias and major depression lifetime prevalence. Soc Psychiatry Psychiatr Epidemiol, 38(6), 290-296, doi:10.1007/s00127-003-0649-9. 